\title{
O PROFESSOR E A TECNOLOGIA: O IMPACTO DO USO DAS TIC'S NO PROCESSO DE ENSINO-APRENDIZAGEM
}

\section{ARTIGO ORIGINAL}

SANTOS, Ari de Sousa ${ }^{1}$

ESMERALDO, Guilherme Álvaro Rodrigues Maia ${ }^{2}$

FERRAZ, Jairo Menezes de ${ }^{3}$

SANTOS, Ari de Sousa. ESMERALDO, Guilherme Álvaro Rodrigues Maia. FERRAZ, Jairo Menezes de. O professor e a tecnologia: O Impacto do Uso das TIC's no Processo de Ensino-Aprendizagem. Revista Científica Multidisciplinar Núcleo do Conhecimento. Ano 05, Ed. 01, Vol. 06, pp. 205-217. Janeiro de 2020. ISSN: 24480959, Link de acesso: https://www.nucleodoconhecimento.com.br/educacao/professor-e-atecnologia

${ }^{1}$ Pós-Graduação: Especialização Em Docência Do Ensino Superior E Especialização Em Informática Na Educação Na Modalidade Ead. Graduação: Letras-Licenciatura Hab. Em Língua Portuguesa, Inglesa E Respectivas Literaturas.

2 Doutorado em Ciências da Computação. Mestrado em Ciências da Computação. Especialização em Engenharia de Desenvolvimento de Projetos Eletrônicos. Graduação em Matemática. Graduação em Bacharelado em Ciências da Computação.

${ }^{3}$ Mestrado profissional em Engenharia de Software. Especialização em andamento em Redes de Computadores. Especialização em andamento em Formação de Professores para o Ensino Superior. Especialização em Gestão de Projetos de TI. Graduação em Automação Industrial. 


\section{RESUMO}

Neste artigo, ressalta-se a presença da tecnologia na educação e a importância do professor como o mediador entre estudante e a informação, esta por sua vez, em virtude da rapidez a qual vem sendo processada por meio de aparelhos, aplicativos e outros meios de massa, precisa ser digerida de forma que o estudante possa compreender a atualidade e tirar bons resultados da manifestação desses amparos tecnológicos na educação. Mediante esse contexto e por meio da pesquisa bibliográfica, considera-se pertinente investigar: Qual o papel do professor mediante o Impacto do uso das TIC's no processo de ensino-aprendizagem? Ressalta-se que tal questionamento, leva ao objetivo desse trabalho que incide em descrever como o professor e a tecnologia tem colaborado no processo de ensino-aprendizagem de forma a não anular a presença física do docente. O presente trabalho fundamenta-se teoricamente nos principais autores: Rojo (2013), Garcia et al. (2011), Mercado (1998), Teles et al. (2018), Lapa e Pretto (2010) e Kubata et al. (2012). Por fim, conclui que o professor continua sendo importante no processo de ensino aprendizagem, no entanto, este profissional deixou de ser o detentor do saber e tornou-se em um mediador entre o ensino e o educando.

Palavras-chave: Professor, tecnologia, ensino, aprendizagem.

\section{INTRODUÇÃO}

A função do professor na escola é sem dúvidas de fundamental importância e ajuíza a sociedade sobre aspectos preponderantes gerados pela participação direta deste individuo no contexto social, pois ele é o agente responsável pela formação de cidadãos que outrora careciam de uma visão ampla de sociedade.

No entanto, na atualidade o docente tem enfrentado novos desafios no processo de ensino-aprendizagem, que segundo Teles et al. (2018), é constatado com o avanço da tecnologia frente as práticas educacionais. Dentro desse debate, o autor salienta que "o aluno contemporâneo é um dos aspectos que exige do professor novas competências que precisa ser contemplada em seu processo de formação inicial e 
continuada". Tendo em vista, o contexto ao qual o aluno está inserido, diante de informações complexas, que exige assim, uma responsabilidade maior de um profissional que contribui de forma significativa para a construção do conhecimento intelectual.

O uso da tecnologia na educação, dinamizou e melhorou consideravelmente o ensinoaprendizagem, levando-o a nível mais elevado, fazendo com que alunos e professores desempenhem suas atividades com prazer ao tempo que possibilita a inserção dos indivíduos ao mundo globalizado. A julgamento bibliográfico especializado, este trabalho, faz uma análise da utilização de ferramentas tecnológicas em salas de aula. Tendo vista que, cada vez mais, exige do docente uma didática moderna onde a tecnologia se faça presente e transforma a escola em um ambiente que usa de forma coerente este artifício, uma vez que, fora da escola a expansão midiática tem surgido de forma acelerada. Assim, a globalização estabelece uma nova metodologia em todos os segmentos da sociedade, essa por sua vez, deve adequar-se para que os cidadãos acompanhem as mudanças ora impostas pela tecnologia. Mediante, tal contexto, o papel do professor é fundamental e indispensável para que o processo de ensino-aprendizagem não seja abalado de forma drástica frente as transformações ocorridas, ao contrário, que constitua uma porta de oportunidade, onde as ferramentas tecnológicas possam estabelecer um elo entre o aprendiz e os novos modelos de recursos.

Refletir sobre o papel do docente em sala de aula é uma atitude de valorização para com este profissional, pois de acordo com os autores Kubata et al. (2012), fazendo uma referencia a Rodrigues (2008), no passado os docentes sentiam-se orgulho de exercer tal profissão, sabe-se que os tempos mudaram e com ele a valorização do professor foi esquecida, é necessário resgatar a credibilidade profissional deste individuo, embora os tempos sejam outros.

A expansão tecnológica tem levado aos centros de ensino uma nova forma de pensar o ensino-aprendizagem, desse modo, observa-se que o professor nesse cenário de mudanças, como agente ativo no processo de ensino-aprendizagem deve estar em 
constante busca das capacidades que a tecnologia dispõe para bem orientar os educandos de forma que corresponda aos seus anseios.

De acordo com as ideias defendidas por Mercado (1998), o setor educacional enfrenta além do desafio de incorporar as novas tecnologias como conteúdo do ensino, a falta do reconhecimento, a partir das percepções que o educador tem sobre as tecnologias para elaborar, desenvolver e avaliar práticas pedagógicas que venha desenvolver um habito reflexivo sobre os conhecimentos e os usos tecnológicos.

Tendo em vista a formação que o docente adquiriu ao longo da história da educação, sabe-se que o mesmo não está preparado para lidar com as transformações repentinas ao longo das últimas décadas, e é por esta razão que seja necessário viabilizar estudos e pesquisa no sentido de despertar nestes profissionais um maior enjangamento no mundo tecnológico.

\section{NOVAS COMPETÊNCIAS DO DOCENTE ANVERSO ÀS TIC'S}

Com o avanço tecnológico, tem surgido a necessidade do professor, adaptar-se ao novo paradigma exigido pela educação, uma vez que a tecnologia tem proporcionado uma ramificação de interlocução por meio das redes sociais e aplicativos, e com isso, exige-se do docente um novo olhar sob o aspecto do ensino- aprendizagem. Parafraseando Garcia et al. (2011), ao decorrer da história, a tecnologia tem modificado a conduta das pessoas e pode provocar um desacerto entre quem ensina e quem aprende e de maneira inevitável, surgem questões a serem repensadas na educação.

Diante disso, os docentes carecem de um desenvolvimento de competências que adequem as tecnologias em salas de aulas. Segundo Lapa e Pretto, (2010, p. 82), "essa instabilidade torna-se um momento potencial para a reflexão sobre a educação, com a possibilidade de ressignificação do papel de docente, proporcionando a transformação". De acordo com Kubata et al. (2012), analisando a vigência da tecnologia atual, é simples aceitar que a TV, a Internet e todos os outros meios tecnológicos de comunicação, são afluências infiéis para a escola, os discentes 
contemporâneos são bem ativos e necessitam de um cuidado particular do professor neste sentido.

Experimentando um senso crítico em relevância das novas competências do docente, o Centro de Inovação para a Educação Brasileira (Cieb), na data do dia 24 de janeiro de 2018, publicou em seu portal 12 (dose) competências que o professor deve adquirir para o uso das TIC's em sala de aula, o documento está subdividido em 03 (três) dimensões de acordo com a seguinte estrutura:

QUADRO 1 - Competências do Docente anverso as TIC's.

\section{1ª DIMENSÃO - PEDAGÓGICA}

Prática Pedagógica: Ser capaz de incorporar tecnologia às experiências de aprendizagem dos alunos e nas suas estratégias de ensino.

Avaliação: Ser capaz de usar tecnologias digitais para acompanhar e orientar o processo de aprendizagem e avaliar o desempenho dos alunos.

Personalização: Ser capaz de utilizar a tecnologia para criar experiências de aprendizagem que atendam as necessidades de cada estudante.

Curadoria e Criação: Ser capaz de selecionar e criar recursos digitais que contribuam para os processos de ensino-aprendizagem e gestão de sala de aula.

\section{DIMENSÃO - CIDADANIA DIGITAL}

Cidadania: Ser capaz de utilizar TIC's para incentivar a participação social e cívica, promovendo a cidadania digital.

Uso Responsável: Ser capaz de fazer e promover o uso responsável da tecnologia (privacidade, rastro digital e implicações legais). 
Uso Crítico: Ser capaz de fazer e promover a interpretação crítica das informações disponíveis em mídias digitais.

Inclusão: Ser capaz de utilizar recursos tecnológicos para promover a inclusão e a equidade educativa.

\section{3" DIMENSÃO - DESENVOLVIMENTO PROFISSIONAL}

Autodesenvolvimento: Ser capaz de usar TICs nas atividades de formação continuada e de desenvolvimento profissional.

Autoavaliação: Ser capaz de utilizar as TIC para avaliar a sua prática docente e implementar ações para melhorias.

Compartilhamento: Ser capaz de usar a tecnologia para promover e participar em comunidades de aprendizagem e trocas entre pares.

Comunicação: Ser capaz de utilizar tecnologias para manter comunicação ativa, sistemática e eficiente com os atores da comunidade educativa.

Disponível em: inoveduc.com.br/cieb-competencias-tics-professor. Acesso em:08 abril 2019.

Seguindo o entendimento desta publicação, destaca-se que as competências mencionadas são essenciais para o profissional da educação. Conforme Rojo (2013) um ensino eficiente precisa propor a função de fornecer competências e conhecimentos os quais os discentes carecem para atuarem na nova sociedade que sob o aspecto digital vivencia uma cultura inovadora e exige do profissional habilidades. Para Garcia et al. (2011), estes fatores são elementos cruciais para a integração da tecnologia no processo educativo, além do conhecimento, seria necessário oferecer aos docentes recursos tais como software e hardware, um desenvolvimento profissional efetivo, tempo suficiente e suporte técnico.

Em consonância com estas competências faz-se necessário reconhecer que a ascensão à tecnologia e programas de formação pode cooperar expressivamente 
para que o educador se sinta mais preparado e capacitado para o uso didático das tecnologias, uma vez que, "não há mais espaço para professores que trabalham apenas conteúdo específicos..., pois esses valores e sua fixação são responsabilidade de todos", (ANTUNES, 2002, p. 108). Por esta razão, o docente necessita compromete-se com a aprendizagem do aluno como um todo, a educação atual exige desse profissional um conhecimento que vai além da matéria a qual leciona, sendo desafiado a olhar o novo o qual passa pelo o uso das tecnologias da informação e comunicação (TIC's), na prática educacional.

\subsection{FORMAÇÃO PEDAGÓGICA MEDIANTE AS NOVAS COMPETÊNCIAS}

Para Garcia et al. (2011, p. 80):

[...] superar o paradigma tradicional ainda hegemônico implica, entretanto, (re) pensar o papel e as competências docentes para lidar com as necessidades atuais de formação bem como a organização da sala de aula, já que sua configuração não é mais a mesma de anos atrás.

Todavia, essa necessidade de pensar em uma estratégia que seja aceitável mediante as novas exigências de aprendizagem que muitas vezes são ignoradas, passa por um paradigma onde seja possível uma aproximação entre o aluno, o professor e as TIC's, já que são esses os autores desse novo panorama da educação.

Mediante esse cenário cabe ao educador a busca incessante por capacitação, sobre esse assunto, assim descreve Mercado (1998, p. 04):

A formação de professores sinaliza para uma organização curricular inovadora que, ao ultrapassar a forma tradicional de organização curricular, estabelece novas relações entre a teoria e a prática. Oferece condições para a emergência do trabalho coletivo e interdisciplinar e possibilite a aquisição de uma competência técnica e política que permita ao educador se situar criticamente no novo espaço tecnológico. 
Segundo o autor a formação do docente mediante esse cenário tecnológico não tem sido levado a sério pelas políticas públicas em educação e nem pelas instituições responsáveis pela capacitação destes profissionais. Contudo, é de extrema importância que se faça uma análise do avanço das competências do professor na utilização destes recursos tecnológico em sala de aula, "isto é, as estratégias de ação, as práticas pedagógicas, a maneira como se abordam os conteúdos e as interações entre professor e o objeto de estudo" Garcia et al. (2011, p. 80).

No entanto, o docente como mediador do processo de ensino-aprendizagem jamais pode desconhecer as competências inerentes a sua atividade e deve sempre refletir suas práticas educativas, inovando seu currículo e proporcionando o prazer do saber.

\subsection{INTERATIVIDADE EM SALA DE AULA}

Analisando o novo perfil exigido ao docente cabe ressaltar que, ao dominar tais capacidades, o professor está preparado para inserir, em suas práticas pedagógicas, a interatividade a qual é intermediada por meio das tecnologias da informação e comunicação. Exemplificando a definição de interatividade e perfazendo uma compreensão da função das TIC's na esfera educacional, pode-se realizar a seguinte observação:

Os principais indicadores de tecnologia interativa envolvem: $O$ intercâmbio entre as máquinas; $O$ intercâmbio entre os usuários e o software; As oportunidades de aprendizagem, entretenimento, aquisição de informação, comunicação em tempo real, comunicação remota; Sistema dinâmico; poder de decisão; Feedbacks; animações; Vídeos; Musica; hipertexto e jogos, Simulações holográficas, Similaridade com o real, Imersão passiva ou ativa, individual ou coletiva e Transformação do entorno virtual. (GARCIA et al 2011, p. 82 apud VERASZTO et al 2009).

As novas competências do docente estabelecem uma correlação de afetividade com as tecnologias da informação e comunicação (TIC's) permitindo o desenvolvimento do ensino-aprendizagem por meio, por exemplo, de ferramentas móveis, que é um 
equipamento que proporciona a interatividade. Para Rojo e Moura (2012), é necessário o uso da tecnologia e dos materiais didáticas digitais em sala de aula para que a escola seja incluída no contexto tecnológico da sociedade contemporânea, na qual as informações são propagadas de maneira rápida e interativa através dos textos digitais. Ainda de acordo com Rojo (2013) é indispensável observar a conjuntura a qual a educação foi construída no passado para entender a necessidade do aluno nativo digital, como a mesma assim o denomina, para só então compreender que no futuro, o educando necessitará de muito mais daquilo que lhe é oferecido no presente.

\section{AS NOVAS TECNOLOGIAS E OS NOVOS DESAFIOS NO ENSINO- APRENDIZAGEM}

De acordo com Galvão Filho (2002), a sociedade atual em que os alunos se desenvolvem, leva-os a dominar prematuramente as novas tecnologias e com isso gera um impacto habitual, tanto na escola como fora dela. Tendo em vista esta prerrogativa, os alunos da presente geração estão bem avançados em relação ao professor quando o assunto é tecnologia, em decorrência da vulnerabilidade tecnológica a qual a sociedade está imergida, pois a internet com toda grandeza tem realizado um processo de mudanças nos hábitos da sociedade escolar, embora seja lento e ainda não há a valorização adequada para este fato. Para Mercado (1998, apud COSTA E XEXÉO 1997), em consequência, deste novo contexto educacional, evidenciam-se a fragilidade das ações e da formação, refletidas também através dos interesses econômicos e políticos que não colaboram com a capacitação dos profissionais da educação.

Os docentes da presente geração confrontam diversos desafios quando o assunto é implementar práticas inovadoras nas escolas. Inovações educacionais não estão ligadas, apenas, à inclusão de ferramentas tecnológicas nos processos de ensinoaprendizagem, mas também é necessário que a metodologia seja modificada, e talvez, este seja o problema mais degradante no meio educacional nos dias atuais, pois "os docentes são (en) formados, seguindo um modelo fechado, pretensamente acabado e determinado em suas verdades" Teles et al, (2018, p 58 apud LIMA e 
LOUREIRO 2015). Frente esse contexto e ainda de acordo com mesma autora, as mudanças ocorridas na sociedade tem transpassado a vida das pessoas, trazendo novas exigências aos cidadãos que necessitam de autonomia, criatividade e senso crítico, tendo desenvoltura para alcançar informações e construir conhecimentos.

\subsection{ASPECTOS DO ALUNO CONTEMPORÂNEO}

Não se pode negar que o aprendiz da atualidade tenha uma característica que a difere dos alunos do passado, pois, como já mencionada, vivemos um novo tempo cercado de computadores, celulares e diversos recursos tecnológicos que leva-os a estarem conectados via internet e consequentemente torna-os familiarizados com o espaço virtual, que segundo Pivato e Oliveira (2014), devido esse novo contexto o qual está inserido o jovem da atualidade, o mesmo deixa de ter apreço pela sala de aula tradicional com seus recursos ultrapassados e que já não produz o conhecimento e nem aptidão a frequência escolar. De acordo com as mesmas autoras, há um crescimento deslumbrante no acesso dos adolescentes a tecnologia, e que isso, tem levado a um embate mediante a realidade a qual a educação sobrevive.

Contudo, se faz pertinente que os docentes juntamente com a escola estejam prontos para lidar com esta nova realidade, e assim, desenvolvam uma educação nos moldes eficazes e que correspondam aos anseios da clientela contemporânea, assim descreve Pivato e Oliveira, (2014, p. 324):

Como manter as práticas pedagógicas atualizadas com esses novos processos de transação de conhecimento? Não se trata aqui de usar as tecnologias a qualquer custo, mas sim de acompanhar consciente e deliberadamente uma mudança de civilização que questiona profundamente as formas institucionais, as mentalidades e a cultura dos sistemas educacionais tradicionais e, sobretudo os papéis de professor e aluno (apud LÉVY, 1999, p. 172).

Segundo Galvão Filho (2002, p. 03 apud PRETTO 1996, p.), as TIC's estão permitindo e ao mesmo tempo entusiasmando o ingresso de valores diversificados de uma nova 
razão que, portanto, gera uma transformação na sociedade como um todo. Em meio a essas mudanças, o docente deve segui-la tomando rumos a desenvolver a função com mais abertura, no sentido de cooperação e interatividade com o aprendiz e os recursos tecnológicos. Ainda de acordo com o autor, "essa mudança significa tornar o aluno, cada vez mais, sujeito de seus próprios processos".

Todavia, o perfil deste aluno moderno que está em constante contato com a informática subtrai do docente a função de detentor do saber, transformando-o em colaborador, parceiro e mediador do conhecimento. $\mathrm{O}$ uso dos recursos digitais na educação potencializa o conhecimento já adquirido dos alunos, por meio do acesso organizado, as ferramentas expandidas de comunicação, interação e difusão do conhecimento, os quais são abertas aos discentes dessa nova geração, (Garcia et al. 2011). "Este novo universo, traz consigo novas exigências aos indivíduos que precisam ser autônomos, criativos e críticos, tendo habilidade para obter e selecionar informações e para construir conhecimentos." Teles et al. (2018, p. 58 ).

A possibilidade que o educando possui de estar integrado a internet torna-o um ser promíscuo, que segundo Pivato e Oliveira (2014), o docente tem o dever de orientálo, para que no seu dia a dia o estudante tenha a oportunidade de desenvolver capacidades pertinentes ao entendimento social, mediante a comunidade digital, fazendo uso dos recursos tecnológicos no campo educacional de forma consciente e responsável.

Porém, sabe-se que a aceitação digital ainda não é vista com bons olhos pelos próprios profissionais da educação, sobre esse assunto afirmam Pivato e Oliveira (2014, p. 326-327):

Atualmente, encontramos nas escolas certa resistência por parte de orientadores, diretores, e até de outros professores quanto ao uso do uso de tecnologias móveis, como celulares e tablets, a serviço da educação nas salas de aula. Diante deste desafio, a comunidade internacional interessou- se pelo assunto, de modo que a Organização das Nações Unidas para a Educação a Ciência e a Cultura - UNESCO, 
publicou um guia contendo significativas recomendações políticas que visam auxiliar os governos na efetivação desses recursos nas salas de aula, enumerando motivos que demonstram vantagens de tal uso para a educação (apud GOMES 2014).

Como é perceptível a aversão ao uso da tecnologia como recurso didático, é mais um desafio a ser superado. Embora grande parte da sociedade esteja vivenciando modificações e tendo novas experiências com o virtual, na escola a resistência ainda se faz prevalecer, como por exemplo, o manuseio do celular em sala de aula é praticamente proibido. O que para Pivato e Oliveira (2014), não deveria acontecer, ao invés da repressão o professor deveria inseri-lo como ferramenta que auxiliaria no ensino e aprendizagem. Ressalta-se o papel do educador como 0 ator principal na equipe pedagógica que é capaz de colocar como meta final a aprendizagem do educando, (Garcia et al. 2011).

\section{CONSIDERAÇÕES FINAIS}

Após a análise deste novo contexto educacional, conclui-se que mediante o desenvolvimento tecnológico ao qual este setor tem passado, o docente mesmo tendo ocupado um novo protótipo em consequência das novas competências exigidas pela manifestação das TIC's em sala de aula, continua sendo o ator principal na educação e cabe a ele a tarefa de adaptar-se e integrar seus alunos ao mundo virtual. E quando se fala em integrar o estudante às Tecnologias da Informação e Comunicação referese a educá-lo no uso adequado destas ferramentas, uma vez que estes já possuem interação com a tecnologia. No entanto, ainda são imaturos no uso destas, a favor do seu aprendizado, pois de acordo com Garcia et al. (2011), a revolução no ensino não passa pelo ingresso de qualquer forma das TIC's no contexto educacional, mas, pelo seu uso crítico e consciente.

Portanto, para que o processo de ensino-aprendizagem ocorra dentro desta nova conjuntura, é necessário o desprender do passado e assumir o desenvolvimento moderno ao qual as TIC's têm proporcionado, fazendo com que a escola se torne um ambiente agradável aos educandos e educadores, sem perder de vista a credibilidade 
do docente que diante das novas habilidades educacionais deve ser um incentivador da aprendizagem e do pensamento crítico. Tendo em vista, que as TIC's possuem um fator de inclusão social, cabe ressaltar, que há diversas maneiras de utilizá-las, inclusive em desfavor da educação. Este trabalho buscou contemplar a sua importância para o processo de ensino-aprendizagem, tendo no professor a confiança de que este, terá atitude de incorporá-la em suas práticas educativas.

\section{REFERÊNCIAS}

ANTUNES, C. Novas maneiras de ensinar. Novas maneiras de aprender. Porto Alegre: Artmed, 2002.

BRASIL. Lei $n^{\circ}$. 9.394 de 20 de dezembro de 1996. Ministério da Educação. Disponível em: <http://portal.mec.gov.br/seesp/arquivos/pdf/lei9394_ldbn1.pdf>. Acesso em: 15 abril 2019.

GALVÃO, F. T. As novas tecnologias na escola e no mundo atual: fator de inclusão social aluno com necessidades especiais? In: Anais do III Congresso IberoAmericano de Informática na Educação Especial. Fortaleza: MEC, 2002. Disponível em: https://www.galvaofilho.net/comunica.pdf. Acesso em: 08 abril 2019.

GARCIA, M. F. (el at). Novas competências docentes frente às tecnologias digitais interativas. Revista Teoria e Prática da Educação. Campinas- SP. V. 14. N.1.p.7687. Jan/abr $2011 . \quad$ Disponível em $<$ https://www.academia.edu/24882516/Novas_Competencias_Docentes_Frente_As_ Tecnologias_Digitais_Interativas>. Acesso em: 05 abril 2019.

KUBATA, L. (et al). A postura do professor em sala de aula: atitudes que promovem bons comportamentos e alto rendimento educacional. Revista Eletrônica de Letras. v. 3. n. $1 . \quad$ p. 1-26. Fev. 2012. Disponível em: $<$ https://www.google.com/search?q=a+postura+do+professor+em+sala+de+aula\%3a +atitudes+que+promovem+bons+comportamentos+e+alto+rendimento+educacional \&oq>. Acesso em: 22 abril 2019. 
LAPA, A. PRETTO, N. L. Educação a distância e precarização do trabalho docente. Em Aberto. Brasília. V. 23. N.84. p. 79-97. Nov. 2010. Disponível em: $<$ https://www.repositorio.ufba.br/ri/bitstream/ri/5569/1/1792-7441-1-PB.pdf>. Acesso em: 03 abril 2019.

MERCADO, L. P. L. Formação docente e novas tecnologias. In: IV Congresso RIBE. Ed. 3. 1998. Brasília. Anais do IV Congresso RIBES. Brasília. UFA.1998. 57-65. Disponível em: $<$ https://www.ufrgs.br/niee/eventos/RIBIE/1998/pdf/com_pos_dem/210M.pdf>. Acesso em: 30 mar 2019.

PIVATO, M. G.; OLIVEIRA, M.R. F. O uso das novas tecnologias educacionais com alunos do $3^{\circ}$ ano do ensino médio. In: III Jornada de Didáticas e Desafios para a Docência e II Seminário de Pesquisa do CEMAD. Ed. 3. 2014. Londrina/PR. Anais da III Jornada de Didáticas e Desafios para a Docência e II Seminário de Pesquisa do CEMAD. Londrina. UEPR. 2014. p. 318-328. Disponível em: <https://www.uel.br.ouso-das-tecnologias-educacionais-com-alunos- do-3-ano-do-ensino-medio-pdf $>$. Acesso em: 23 abril 2019.

ROJO, R. (Org.). Escol@ Conectada: os multiletramentos e as TIC's. $1^{\text {a }}$ ed. São Paulo/SP. Parábola. 2013.

SANTOS, C. L.; SPENA, G.; MOURA, M. A função do docente no processo deensino-aprendizagem. 2006 Disponível $<$ https://paginapessoal.utfpr.edu.br/mansano/arquivo/art_cofop24_glauco.doc/at.../fil è. Acesso em 20 abril 2019.

SANTOS, L. Cieb indica competências necessárias para uso de TICs por professores. INOVEDUC Folha Dirigida. Versão online. Jan 2018. Disponível em: <inoveduc.com.br/cieb-competencias-tics-professor>. Acesso em: 08 abril 2019.

TELES, G. (et al), Docência e tecnologias digitais da informação e comunicação: matriz curriculares das licenciaturas. In: III Congresso sobre Tecnologias na Educação. Ed. 3.2018. Fortaleza/CE. Anais do III Congresso sobre tecnologias na 
educação. Fortaleza. UFC. 2018. p. 57-67. Disponível em: <https://www.ceurws.org/Vol-2185/CtrIE_2018_paper_12_pdf>. Acesso em: 15 abril 2019.

Enviado: Outubro, 2019.

Aprovado: Janeiro, 2020. 